\section{$\underset{\substack{\text { hommes } \\ \text { \& migrations }}}{ }$}

\section{Hommes \& migrations}

Revue française de référence sur les dynamiques

migratoires

\section{3 | 2011}

L'immigration dans les musées

\title{
Ali Magoudi, Un sujet français
}

Paris, Albin Michel, 2011, 406 pages, 23 euros

\section{Mustapha Harzoune}

\section{Q OpenEdition}

1 Journals

\section{Édition électronique}

URL : http://journals.openedition.org/hommesmigrations/544

DOI : 10.4000/hommesmigrations.544

ISSN : 2262-3353

\section{Éditeur}

Musée national de l'histoire de l'immigration

\section{Édition imprimée}

Date de publication : 1 septembre 2011

Pagination : 158-159

ISSN : 1142-852X

\section{Référence électronique}

Mustapha Harzoune, «Ali Magoudi, Un sujet français », Hommes \& migrations [En ligne], 1293 | 2011 , mis en ligne le 29 mai 2013, consulté le 22 septembre 2020. URL : http://journals.openedition.org/ hommesmigrations/544; DOI : https://doi.org/10.4000/hommesmigrations.544

Ce document a été généré automatiquement le 22 septembre 2020.

Tous droits réservés 


\title{
Ali Magoudi, Un sujet français
}

Paris, Albin Michel, 2011, 406 pages, 23 euros

\author{
Mustapha Harzoune
}

\section{RÉFÉRENCE}

Ali Magoudi, Un sujet français, Paris, Albin Michel, 2011, 406 pages, 23 euros

1 Trente-sept ans après la mort de son père, le chirurgien, psychanalyste et écrivain Ali Magoudi décide d'en raconter la vie. Poussé par une lointaine et troublante exhortation paternelle qui veut qu'un jour son fils couche sur le papier l'histoire de son géniteur, il s'en va traquer les méandres du passé.

2 Mais voilà ! Papa Magoudi, comme bien des pères algériens de cette génération, n'était pas un bavard. Privés de parole dans l'espace public, ces migrants d'un autre temps étaient du genre taciturne à la maison. Quant à maman Magoudi, Eugenia Bronislawa, sa mémoire se révélera à géométrie variable.

3 La question qui se pose est : quel est l'intérêt pour le commun des lecteurs que cette vie reconstituée et restituée par son rejeton ? Deux pistes s'ouvrent, celle de la psychologie individuelle et celle de l'histoire collective. Un tel récit peut nous en apprendre sur nos sociétés comme il pourrait nous éclairer sur nous-mêmes. La question est de savoir quelle satisfaction, quel enseignement l'on retire de ce cheminement sur un texte au fort dénivelé chronologique.

4 L'auteur, “Rigoureux. Systématique. Ordonné", comme il se plaît à se définir et à le répéter, décrit par le menu ses recherches, la consultation des archives de la police, des archives militaires, nationales, départementales, des archives des hôpitaux de Paris, des écoles, d'entreprises privées... Un véritable vade-mecum du parfait petit généalogiste ou de l'enquêteur en micro-histoire. Tout cela est long et fastidieux. Pour lui, mais aussi pour le lecteur. Comme sont déroutants le méli-mélo des dates, l'entassement des souvenirs et des trouvailles. Entre les détails pointilleux, les descriptions minutieuses, la reproduction de ses missives, quelques digressions intempestives ou autosatisfaites, les 
supputations et autres hypothèses servie à tire-larigot, on frise, plus d'une fois, le tropplein. On est loin de l'élégante efficacité d'Origines d'Amin Maalouf.

5 Ali Magoudi est donc le fils d'une Polonaise catholique et d'un Algérien musulman. Gueule de bougnoule mais âme de Polack, c'est un Polonais qui se cache à l'intérieur d'un corps d'Arabe. Malgré son prénom et son patronyme, "le psychanalyste des présidents" n'a eu que peu ou pas de rapports avec la branche algérienne de sa famille et avec la culture et la langue paternelles. Ou si peu. Au point que, comme il l'écrit luimême, il a chassé l'Arabe qui est en lui. Les voies de l'identité sont impénétrables et les dessous de la psyché peut-être plus encore.

6 Au bout de ces trois ans d'enquête, qu'a appris le fiston? D'abord, puisque tel est le titre du livre, lui qui considérait son père comme Français découvre que papa Magoudi, aux yeux de son pays, la France, était un "sujet français". Ainsi Ali Magoudi s'aperçoit que les Algériens dans l'Algérie de papa n'avaient pas droit à la nationalité française mais pouvaient s'estimer heureux d'être reconnus pour des "sujets français". "Français musulman"? Oui ! "Français de droit commun"? Non! Ali Magoudi comprend donc que son père n'était, aux yeux de l'histoire et de la société française, qu'un "Nord-Af"! Dans la chaîne de la filiation, parler de "brisure générationnelle irréparable" relève sans doute de l'euphémisme.

7 Abdelkader Magoudi fut donc un "sujet français", né au temps heureux de l'apartheid colonial, immigré nord-africain dans une métropole soupçonneuse, il a dû combiner avec l'occupation allemande, Vichy, l'expansion nazie, le communisme en Pologne et même avec la décolonisation et bazarder le funeste et ascétique socialisme de Boumediene. Les "effacements de l'histoire" prospèrent. Des contemporains s'en satisfont, s'en accommodent, s'en dépatouillent. D'autres butent dessus, voient leurs horizons entravés, leur liberté compromise. Ces "effacements" ici sont nombreux : "la destruction des juifs de Plock", le martyre de Varsovie, la colonisation, la Brigade nord-africaine qui ficha tous les "Nord-Af" de 1925 à 1945 ou encore le télescopage de la rafle du Vel d'Hiv et de l'histoire personnelle du narrateur.

8 Ali Magoudi débusque aussi quelques secrets de famille, lève des silences mais rien qui n'appartienne au paysage familial, voilé d'ombre et nimbé de lumière, de tout un chacun. De ces trouvailles, Ali Magoudi explique, ex-post, comme disent les économistes, certains de ses comportements. Il retrouve les échos de l'histoire familiale dans l'histoire personnelle de chacun des enfants Magoudi. Il piste le cheminement des faits retrouvés dans l'âme des uns et des autres, comment ils se sont infiltrés pour en modeler les peurs et les frustrations, les contours et les résistances. Cela ravira les détectives ès psychologie, les aventuriers de la psyché, les Indiana Jones de l'âme.

Cette enquête offre aussi l'occasion d'ouvrir une réflexion sur le statut du silence: jusqu'où les silences nous oppriment-ils et quand nous délivrent-ils? Peut-on se libérer et libérer les siens du fatum familial sans devoir "grimper l'arbre du savoir", grimper parfois jusqu'au vertige ? Midek, le frère aîné, ne partage pas la passion introspective de son petit frère. Faut-il interroger son refoulement ou plutôt "les raisons profondes" qui animent l'auteur de ce livre et de cette quête insurmontable? Car après avoir refermé le livre, on a parfois l'impression qu'il n'y a rien là qu'une vie banale. Peut-être est-ce la différence entre une intelligence et une sensibilité fines et un esprit frustre et superficiel... Pourtant, dans le maquis des hypothèses, l'auteur en arrive à dresser ce constat: "Mon père a eu une vie sans aspérité particulière dans l'avant-guerre comme pendant la guerre." 
10 Ali Magoudi ne saura pas tout. Le passé ne livrera pas tout son mystère. Son père repose pour l'éternité avec ses silences et des pans entiers de son existence. Le vertige de la connaissance et du savoir chemine sur une ligne de crête, entre illusion et néant.

11 D'ailleurs, on en apprend peut-être plus sur l'auteur que sur son père, "sujet français" de la France coloniale mais aussi sujet de cette enquête-étude, où parfois le père paraît par trop désincarné dans un texte captivant, ficelé en diable. Intellectuel aussi : on est loin des évocations paternelles de Magyd Cherfi, Mouloud Akkouche ou Ahmed Kalouaz.

12 Une fois, Ali Magoudi imagine les paroles de son père : "Cesse de me regarder avec tes yeux d'enfant, la vie d'adulte n'est pas innocente. Cesse de me juger avec ton intelligence de docteur, insensible à la honte qui m'a tant fait boire. Si tu es qui tu es, tu me le dois, ne l'oublie jamais! (...) Que me reproches-tu encore? Ah, toujours mes silences! Survivre, j'ai eu à survivre, chose incompréhensible pour toi qui n'as eu qu'à vivre."

13 Reste une question : pourquoi cet Algérien qui, comme bien des siens de sa génération et de celle qui a suivi, s'est débrouillé avec abnégation, sans plaintes, dans le silence, pourquoi prédit-il que son rejeton finira par écrire son histoire? Que cache cette exhortation sur le lien entre les deux hommes? Que dit-elle du regard que pose le père sur son fils, du regard d'un Algérien sur ce fils devenu aussi un Autre ? De cela nul n'en saura jamais rien. 